\title{
Anomalous origin of the left vertebral artery in humans: A rare anatomical finding?
}

\author{
José Aderval Aragão ${ }^{1 *}$, Júlio César Claudino Dos Santos ${ }^{2}$, Dhayanna Rolemberg Gama Cabral ${ }^{3}$, \\ Carlos Augusto De Oliveira Filho ${ }^{4}$, Henrique Pereira Barros 5 \\ ${ }^{1}$ Associado Professor I, Department of Morphology and the Postgraduate Physical Education and Applied Health Sciences \\ Programs, Federal University of Sergipe (UFS), and Titular Professor of the Medical School, \\ Tiradentes University (UNIT), Aracaju, Sergipe, Brazil \\ ${ }^{2}$ Medical Student, State University of Health Sciences of Alagoas (UNCISAL), Maceió, Alagoas, Brazil \\ ${ }^{3}$ Medical Student, Center for Higher Studies of Maceió (CESMAC), Maceió, Alagoas, Brazil \\ ${ }^{4}$ Medical Student, Tiradentes University (UNIT), Aracaju, Sergipe, Brazil \\ ${ }^{5}$ Adjunct Professor I, Department of Anatomy of University Center Tiradentes (UNIT), Maceió, Alagoas, Brazil. \\ *Corresponding author E-mail: jaafelipe@infonet.com.br
}

Copyright (-) 2015 José Aderval Aragão et al. This is an open access article distributed under the Creative Commons Attribution License, which permits unrestricted use, distribution, and reproduction in any medium, provided the original work is properly cited.

\begin{abstract}
Context: Anatomical and morphological variations of the aortic arch and its branches are important in relation to thoracic and neck surgery. However, developmental abnormalities of the vertebral arteries are generally considered to be very rare. They have mostly been described in single case reports or small series. Thus, there is a need for further knowledge as an aid in planning surgery on the aortic arch or endovascular interventions. Objective: To report on a case of anomalous origin in the left vertebral artery. Case report: In a male cadaver, a left vertebral artery with its origin in the aortic arch between the left common carotid and left subclavian arteries was observed. Its length was $120 \mathrm{~mm}$, and its diameter was $5.5 \mathrm{~mm}$. It entered the transverse foramen of the third cervical vertebra. Conclusion: Knowledge of the anatomical variation of the origin of the vertebral artery is important not only diagnostically but also in planning surgery on the aortic arch or endovascular interventions.
\end{abstract}

Keywords: Anatomical Variations; Vertebral Artery; Aortic Arch; Brachiocephalic Trunk; Subclavian Artery; Common Carotid Artery.

\section{Introduction}

The incidence of branching patterns in the aortic arch (brachiocephalic trunk, left common carotid artery and left subclavian artery) is around 63.5 to $92.7 \%$ [1-7]. Anatomical variations relating to the origin and number of branches of the aortic arch are of fundamental importance in making diagnoses using imaging methods and in the procedures of thoracic and neck surgery [1], [3], [5], [8]. The left vertebral artery usually has its origin in the first part of the left subclavian artery [1], [9-12]. Its origin in the aortic arch may vary in 2.4 to $16.67 \%$ of the cases, although its most frequent location is between the left common carotid artery and the left subclavian artery [3], [5], [7], [13-15]. Embryologically, this anomalous origin of the left vertebral artery is explained by persistence of the sixth intersegmental cervical artery and failure of the dorsal segment of the aorta to disappear [5], [16]. This would lead to blood flow through the persistent routes and would result in alterations to the hemodynamics, which might often predispose the patient towards possible formation of intracranial aneurysm [5], [6], [17], [18]. The present study had the aim of reporting on a case of anomalous origin of the left vertebral artery. 


\section{Case report}

During routine dissection on the chest of a dark-skinned male cadaver of apparent age between 55 and 60 years, belonging to the Anatomy Laboratory of the State Health Sciences University of Alagoas, it was observed that the left vertebral artery originated from the aortic arch, between the left common carotid and left subclavian arteries (Figure 1), with a length of $120 \mathrm{~mm}$ and a diameter of $5.5 \mathrm{~mm}$. After its origin, the first part of the artery followed its normal course and then entered the transverse foramen of the third cervical vertebra (Figure 2).

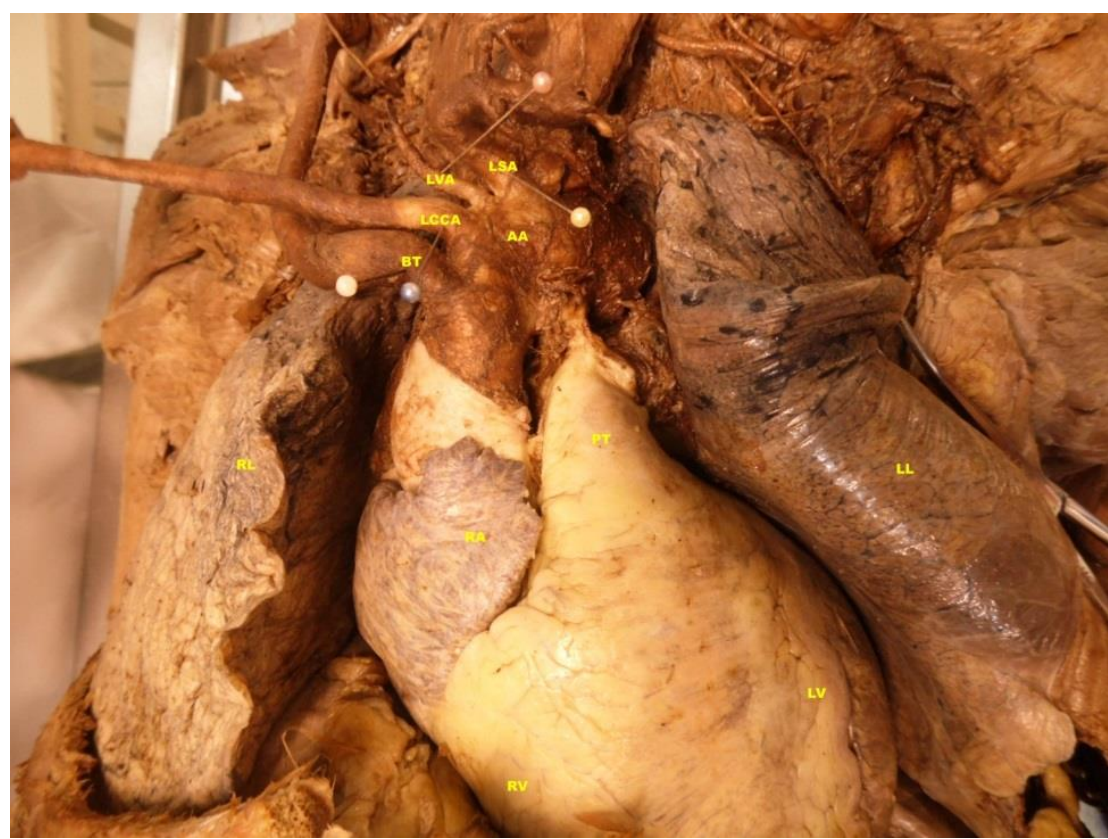

Fig. 1: Anomalous Origin of the Left Vertebral Artery of the Aortic Arch.

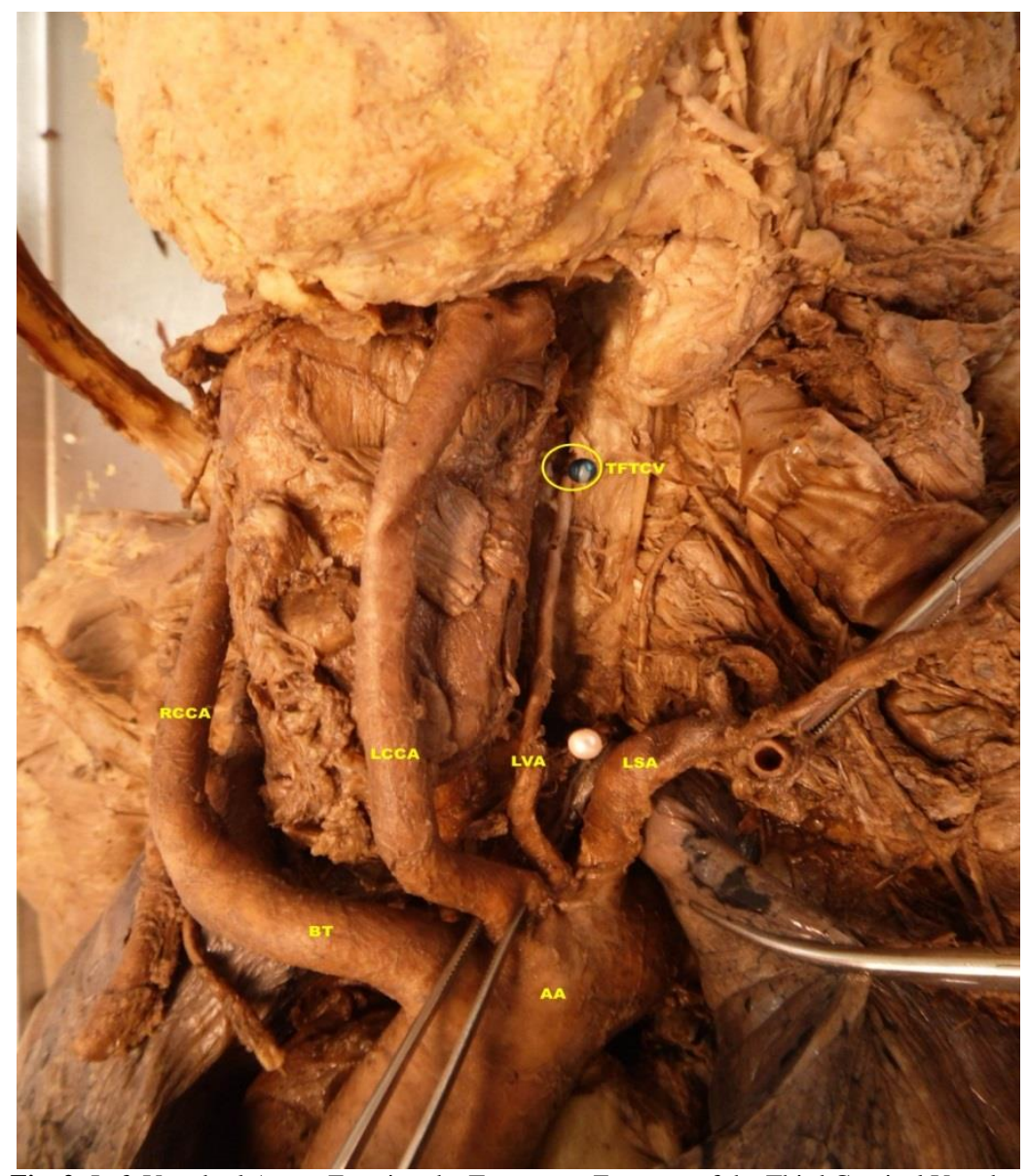

Fig. 2: Left Vertebral Artery Entering the Transverse Foramen of the Third Cervical Vertebra 


\section{Discussion}

Although the anomalous origins of the ramifications of the aortic arch are merely anatomical variations, precise information on these features is vital for vascular surgery in the region of the chest, head and neck. There are usually three branches from the aortic arch: the brachiocephalic trunk, left common carotid artery and left subclavian artery. This pattern is usually observed in around 63.5 to $92.7 \%$ of humans [1], [3], and [5]. However, in around $6 \%$ of the population, the left vertebral artery arises from the aortic arch, generally between the left common carotid and left subclavian arteries [19]. This was concordant with our study, in which we found a left vertebral artery originating in the aortic arch between the common carotid and subclavian arteries. According to some studies, the frequency of an origin in the aortic arch for the left vertebral artery may range from 2.4 to $16.67 \%$ [3], [5], [7], [13], and [14].

The vertebral arteries may enter the transverse foramens of the second to the seventh cervical vertebra. However, in most cases, the left vertebral artery enters the transverse foramen of the sixth cervical vertebra [1], [17], [21]. According to Vikram et al [12] and Patil et al [4]; the vertebral artery entered the transverse foramen of the third cervical vertebra, which was concordant without our study, in which we also found that the vertebral artery entered the transverse foramen of the third cervical vertebra.

After the vertebral artery emerges from the aortic arch, it follows a sinuous ascending path of approximately $120 \mathrm{~mm}$ in length. According to Sikka and Jain [16], this length may vary according to the origin of the vertebral artery, and according to the vertebra at which it enters the transverse foramen.

The diameter of the vertebral artery in our study was $5.5 \mathrm{~mm}$, which was concordant with the findings from the studies by Alsaif and Ramadan [3], Patasi et al [11], Vikram et al [12] and Sikka and Jain [16], in which the diameter ranged from $3.6 \mathrm{~mm}$ to $6.0 \mathrm{~mm}$.

Failure to recognize variation of the vascular anatomy of the aortic arch, favors complications in surgical procedures on the aortic arch. These may include ischemic problems and may put the patient's life at risk [3], [17]. For this reason; knowledge of the possible origins of the left vertebral artery is beneficial both for surgical planning in relation to the aortic arch and for endovascular interventions [8], [12].

\section{Conclusion}

Knowledge of the anatomical and morphological variations of the left vertebral artery is of great importance in imaging diagnostic procedures and in surgical interventions in the head and neck region. For this reason, physicians who are imaging specialists and surgeons need to be aware of these possible variations in order to avoid complications.

\section{References}

[1] Budhiraja V, Rastogi R, Jain V, Bankwar V, Raghuwanshi S. Anatomical variations in the branching pattern of human aortic arch: a cadaveric study from central India. ISRN Anatomy, vol. 2013, Article ID 828969, 5 pages, 2013. doi:10.5402/2013/828969.

[2] Liechty JD, Shields TW, Anson BJ. Variations pertaining to the aortic arches and their branches; with comments on surgically important types. Q Bull Northwest Univ Med Sch. 1957; 31(2):136-43.

[3] Alsaif HA, Ramadan WS. An Anatomical Study of the Aortic Arch Variations. JKAU: Med Sci. 2010; 17(2):37-54. Doi: 10.4197/Med. 172.4.

[4] Patil ST, Meshram MM, Kamdi NY, Kasote AP, Parchand MP. Study on branching pattern of aortic arch in Indian. Anat Cell Biol. 2012 Sep; 45(3):203-6. doi:10.5115/acb.2012.45.3.203.

[5] Lale P, Toprak U, Yagiz G, Kaya T, Uyanik SA. Variations in the Branching Pattern of the Aortic Arch Detected with Computerized Tomography Angiography. Advances in Radiology, vol. 2014, Article ID 969728, 6 pages, 2014. doi:10.1155/2014/969728.

[6] Nayak SR, Pai MM, Prabhu LV, D’Costa S, Shetty P. Anatomical organization of aortic arch variations in the India: embryological basis and review. J Vasc Bras 2006; 5(2):95-100.

[7] Rekha P, Senthilkumar S. A study on branching pattern of human aortic arch and its variations in south indian population. J Morphol Sci. 2013; 30(1):11-15.

[8] Satti SR, Cerniglia CA, Koenigsberg RA. Cervical vertebral artery variations: an anatomic study. AJNR Am J Neuroradiol. 2007 May; 28(5):976-80.

[9] Bhatia K, Ghabriel MN, Henneberg M. Anatomical variations in the branches of the human aortic arch: a recent study of a South Australian population. Folia Morphol (Warsz). 2005 Aug; 64(3):217-23

[10] Kubikova E, Osvaldova M, Mizerakova P, El Falougy H, Benuska J. A variable origin of the vertebral artery. Bratis1 Lek Listy. 2008; 109(1):28-30.

[11] Patasi B, Yeung A, Goodwin S, Jalali A. Anatomical variation of the origin of the left vertebral artery. IJAV. 2009; 2:83-85.

[12] Vikram N, Patil MB, Basavaraj B, Badiger YD. Anatomical variation of the origin of the left vertebral artery: a case report. IJCRR. 2013 Jun; 5(11): 133-136.

[13] Komiyama M, Morikawa T, Nakajima H, Nishikawa M, Yasui T. High incidence of arterial dissection associated with left vertebral artery of aortic origin. Neurol Med Chir (Tokyo). 2001 Jan; 41(1):8-11.

[14] Surya E, Anitha V. Anomalous origin of left vertebral artery arising from the arch of aorta and its embryological basis. Int J Anat Res 2014; 2(3):537-40

[15] Bergman RA, Afifi AK, Miyauchi R. Illustrated Encyclopedia of Human Anatomic Variation: Opus II: Cardiovascular System: Arteries: Head, Neck, and Thorax. $2015 . \quad$ cited 2015 Apr $\quad$ 05]. from.http://www.anatomyatlases.org/AnatomicVariants/Cardiovascular/Text/Arteries/Vertebral.shtml.

[16] Sikka A, Jain A. Bilateral variation in the origin and course of the vertebral artery. Anatomy Research International, vol. 2012, Article ID 580765, 3 pages, 2012. doi:10.1155/2012/580765. 
[17] Shin HY, Park JK, Park SK, Jung GS, Choi YS. Variations in Entrance of Vertebral Artery in Korean Cervical Spine: MDCT-based Analysis. Korean J Pain. 2014 Jul; 27(3):266-70. doi: 10.3344/kjp.2014.27.3.266.

[18] Shoja MM, Tubbs RS, Khaki AA, Shokouhi G, Farahani RM, Moein A. A rare variation of the vertebral artery. Folia Morphol (Warsz). 2006 May; 65(2):167-70.

[19] Koenigsberg RA, Pereira L, Nair B, McCormick D, Schwartzman R. Unusual vertebral artery origins: examples and related pathology. Catheter Cardiovasc Interv. 2003 Jun; 59(2):244-50.

[20] Jamkar AA, Sabnis AS. An unusual variation of vertebral artery. Int J Anat Var (IJAV). 2014; 7:32-34.

[21] Singla RK, Sharma T, Sachdeva K. Variant origin of left vertebral artery. Int J Anat Var (IJAV). 2010; 3:97-99.

\section{Legends of figures}

Figure 1 Anomalous origin of the left vertebral artery of the aortic arch.

RV - Right ventricle

LV - Left ventricle

RA - Right auricle

PT - Pulmonary trunk

AA - Aortic arch

RL - Right lung

LL - Left lung

BT - Brachiocephalic trunk

LCCA - Left common carotid artery

LVA - Left vertebral artery

LSA - Left subclavian artery

Figure 2 Left vertebral artery entering the transverse foramen of the third cervical vertebra

AA - Aortic arch

BT - Brachiocephalic trunk

LCCA - Left common carotid artery

RCCA - Right common carotid artery

LVA - Left vertebral artery

LSA - Left subclavian artery

TFTCV - Transverse foramen of the third cervical vertebra 